\section{Abstract}

Engaging with Indigenous peoples is clearly on the agenda of natural hazard leaders in southern Australia, but there is very little research, policy or practical experience to support this work. Indeed, with a few important exceptions, natural hazard organisations and research institutions have had little engagement with Indigenous peoples, their organisations or research priorities or protocols. While there are substantial gaps in the research evidence, it is important to start identifying the issues at hand and consider what might be done in response. This paper provides a brief overview of the fraught relations between Indigenous and non-Indigenous people in Australia and some common misunderstandings. The paper includes specific suggestions for current research, policy and practice, noting that natural hazard agencies and research institutions are influential and closely related. It is clear there are challenges. However, changing practice is essential to foster more respectful terms between Indigenous peoples and Australia's natural hazard and emergency management sector.

\title{
Indigenous peoples and natural hazard research, policy and practice in southern temperate Australia: an agenda for change
}

Peer Reviewed

Bhiamie Williamson ${ }^{1}$

Dr Jessica Weir ${ }^{1,2}$

1. Australian National University, Canberra, Australian Capital Territory.

2. Western Sydney University, Sydney, New South Wales.

\section{SUBMITTED}

4 June 2021

\section{ACCEPTED}

16 August 2021

DOI

www.doi.org/10.47389/36.4.62

\section{(ㄷ) $(1) \Theta$}

(C) 2021 by the authors. License Australian Institute for Disaster Resilience Melbourne, Australia. This is an open access article distributed under the terms and conditions of the Creative Commons Attribution (CC BY) license (https:// creativecommons.org/ licenses/by/4.0/).

\section{Introduction}

The broad scope of natural hazard research, policy and practice includes concerns relative to Indigenous peoples. However, with a few important exceptions, natural hazard agencies and research institutions have had little engagement with Indigenous peoples, especially in southern Australia (Thomassin et al. 2018, Smith et al. 2021). To understand this, statistics and maps were published showing the Indigenous groups affected by summer bushfires in 2019-20 in Victoria, New South Wales and the Australian Capital Territory to show their numerical presence and unique rights, geographies and population profiles

(Williamson et al. 2020). In addition, 2 important bushfire inquiries were reviewed (McLeod 2003, Teale et al. 2009) and revealed that Indigenous peoples were included only as an historical footnote, as well as in a brief cultural heritage reference (Williamson et al. 2020, p.14-15). A research review into the recommendations of 55 post-disaster inquiries did not mention Indigenous peoples at all, not even whether they were absent or not in the recommendations (Cole et al. 2017).

This lack of engagement is undergoing significant change. During and after Australia's 2019-20 summer bushfires, Indigenous peoples' fire management practices made national and international headlines and were included in the terms of reference and scope for the Victorian, New South Wales and Australian Government inquiries (Binskin et al. 2020, Lay 2020, Owens \& O'Kane 2020). The Victorian Government established an Aboriginal reference group to advise the newly created agency, Bushfire Recovery Victoria, thereby signalling a grasp of issues greater than just fire management (State of Victoria 2021, p.10). Clearly, Indigenous engagement is now on the agenda of public sector decision-makers involved in natural hazards and disaster resilience in southern Australia. However, there 
is very little existing research, policy or practical experience to inform this work. For example, aside from work by Williamson, Markham and Weir (2020), there has been no research on Indigenous peoples and disaster relief and recovery policy in southern temperate Australia. Yet, Indigenous peoples are working within and navigating natural hazard policy, practice and research. Recognised as first nations people, traditional owners and traditional custodians, Indigenous peoples bring to this work their own land, societies, laws and customs.

The terms Indigenous people is used to signify individuals and Indigenous peoples is used to signify political-legal groups.

This paper shows how engaging with Indigenous peoples can be more than an agenda item for natural hazard institutions; it challenges and changes the agenda itself. By natural hazard institutions, we include disaster resilience, relief and recovery, as undertaken across the public sector and by research bodies. Building the competencies of these institutions is an integral step towards supporting Indigenous-led and collaborative approaches in natural hazard research, policy and practice (e.g. Sangha et al. 2019). There is a clear need to transition from the commitments of a few individuals to investing in structural and procedural support (Smith et al. 2021; Weir, Neale \& Smith 2021; Sangha et al. 2019; Ali et al. 2021); otherwise, Indigenous people remain explaining their relevance and always with the pressure to conform to dominant, non-Indigenous approaches (Ellemor 2005, Smith et al. 2021). This wastes time, risks employee burnout and perpetuates platitudes (Freeman et al. 2021). However, this situation is not unique to the natural hazard sector but is indicative of fraught relations held between Indigenous and non-Indigenous people and government organisations, research institutions and in society broadly.

There are many opportunities to research and work differently in southern temperate Australia. This is where the majority of Indigenous people live and also where most natural hazard risks are, as acknowledged by the sector because of non-Indigenous settlement and development patterns (Weir, Sutton \& Catt 2020). It is also where most of our research experience has been gained.

This paper does not replace the priorities of Indigenous peoples, instead it emphasises the appropriate centring of Indigenous voices on Indigenous issues. It is acknowledged how Indigenous identity and authority is understood in relation to context and is often negotiated in intra-Indigenous forums that nonIndigenous people are not privy to (Sullivan 2020). These are complex matters beyond the scope of this paper. However, they require investing in Indigenous governance (Freeman et al. 2021). Indigenous people are first nations, traditional owners, traditional custodians, communities, community leaders, public servants, elders, politicians, researchers, citizens and residents. Indigenous peoples are also diverse in ability, class and sexual orientation. Notably, in comparison to Indigenous men, Indigenous women are marginalised in areas of land and natural hazard management (Cavanagh 2021).

\section{Distorted relations}

The absence of Indigenous peoples and their priorities in natural hazard research, policy and practice is not unique, but part of Australia's psyche of distorted relations (after McGregor 2017). Late 19th and early 20th Century Euro-American logics of racial superiority positioned Indigenous people as backward, uncivilised and presumed their way of life would inevitably give way to white superiority (Moreteen-Robinson 2015). Fundamentally, Indigenous people were not expected to be part of modern Australia. Instead, Indigenous peoples' political-legal entities were incorrectly presumed and relied upon to be absent (Strelein et al. 2001).

A suite of consequences has resulted, as critiqued by generations of Indigenous people whose advocacy and action has led to more just terms. This includes the High Court of Australia Mabo decision ${ }^{1}$ and the subsequent recognition of native title rights. The 20th Century saw a resurgence in Indigenous peoples' cultural and political standing and Australia's adoption of principles of non-discrimination in law and policy. All government jurisdictions in Australia have legislative mechanisms recognising the rights and authority of Indigenous peoples with respect to their land, water, cultural heritage, governance and more. For example, in Victoria the Aboriginal Cultural Heritage Act 2006 and the Traditional Owner Settlement Act 2010. Further, Victorian, Queensland and Northern Territory jurisdictions are currently undertaking discussions with Indigenous groups about treaties.

Indigenous people now have ownership and management rights and interests to almost half the continent, including important lands in southern temperate Australia (Altman \& Markham 2015). In NSW, for example, Local Aboriginal Land Councils are becoming the largest landowners in some local government areas. It is anticipated that all conservation lands will have formal arrangements with Indigenous people within the next 20 years (Norman 2018). In Victoria, it is government policy that all lands will have formally recognised Traditional Owners. As a body, these land tenure changes have profound implications for how Australia is understood and governed. For example, land title is often assumed to be either private or public, but almost half the continent is under communal title, requiring a rethink of models that regulate and fund land-management responsibilities (Weir \& Duff 2017). Land tenure changes have been a catalyst for environmental research institutions and funding bodies, with some now prioritising Indigenous people and Indigenous research methodologies across their programs (Moggridge 2019).

Nonetheless, there remains consequential matters that must be overcome to secure more just terms between Indigenous and non-Indigenous people. One is the viewpoint that distorted relations only require work by, for, and with Indigenous people instead of understanding that addressing distorted relations is everyone's responsibility. This means that non-Indigenous people must also examine their assumptions, institutions and processes (McGregor 2017). Thus, public sector and research institutions must examine how they may benefit from discriminatory structures and processes, both those they work with as well as

\footnotetext{
1. Mabo v Queensland (No 2) [1992] HCA 175 CLR 1.
} 
those they have created and sustain. These are not always easy to identify. There is much in the status quo that is simply taken for granted from non-Indigenous viewpoints. For example, the assumption that Indigenous people are regarded as community stakeholders to governments and in research projects. This leaves Indigenous people with the choice of participating in public sector and research activities on these terms, or not participating at all (Hemming et al. 2010). Instead, specific engagement protocols can be established with Indigenous peoples, also known as self-determination mechanisms. These recognise and support the self-determining authority of Indigenous peoples, including first nations, traditional owners and traditional custodians.

Another consequential matter is the assumption that Indigenous knowledge is local knowledge. Indigenous people have landcentred knowledge-governance systems, known as Country (Kwaymullina 2016, Cavanagh \& Stanley 2021). Key elements include inter-generational ethics within and between Indigenous groups and reciprocal relations with species and natural processes that acknowledge co-dependency (Reo et al. 2017, Latulippe \& Klenk 2020). The most important relationships are held between people and the land and then relationships between people (Graham 2007). This is knowledge that is recognised and shared regionally, nationally and globally. It has useful points of intersection with sustainable development approaches to disaster resilience, which is the general trend of natural hazard research, policy and practice in Australia and internationally (COAG 2011, Lambert \& Scott 2018). However, to categorise Indigenous knowledge as local knowledge, is to exclude it from influencing these and many other influential forums.

The paucity of research about natural hazards and Indigenous peoples reflects the pan-continental Indigenous experience of being co-located with a nation established on non-Indigenous terms and priorities (Weir, Sutton \& Catt 2020). In southern temperate Australia, aside from Williamson, Markhan and Weir (2020) and the small literature on Indigenous fire management, only 2 other papers were found. These were on general cultural heritage matters, mainly European-settler, and identify the lack of expertise in Indigenous heritage in natural hazard research and practice (Graham \& Spennemann 2007, Laidlaw et al. 2007). In northern and central Australia where Indigenous peoples are the majority landholders and often the majority residents, and, aside from the Indigenous fire management literature, the research is limited to a handful of papers (e.g. Haynes et al. 2014, Veland et al. 2010, Ali et al. 2021, Sangha et al. 2019).

Today, Indigenous people face a skewed political economy when meeting with governments, universities and private companies. While some parties work to change the terms of these meetings (Muller et al. 2019), Strelein and co-authors (2019) note:

The interests of traditional owners inevitably end up secondary to those of proponents who, via access to greater resources or superior socio-political positioning, are able to more effectively navigate bureaucracies and secure support from key actors. (p.17).
Fundamentally, when addressing systemic problems, it is critical for policy makers, legislatures, research leaders and others to acknowledge the context; what has come before and continues to inform the present (Bodkin-Andrews \& Carlson 2016, Doyle et al. 2018). Without acknowledging how distorted relations has been created and perpetuated, Indigenous peoples will continue to be type cast as the problem. For example, Indigenous people are often described as vulnerable in disaster contexts with no mention of the assimilation policies that have undermined Indigenous people's existence as peoples, families and individuals, affecting their collective wellbeing (Krieg 2009). By not acknowledging the influence of discriminatory structures and processes, the provision of external expertise is legitimised (Ellemor 2011). When typecast as vulnerable, Indigenous peoples' strengths in kinship, governance and culture are not recognised and supported with self-determination mechanisms. These are not productive grounds for establishing and sustaining collaborative and Indigenous-led approaches.

\section{An agenda for change}

The extensive literature on forming better relationships between Indigenous peoples, governments, universities and others (Kwaymullina 2016, McGregor 2017, Muller et al. 2019, Reo et al. 2017) identified 2 inter-related priorities:

- To centre Indigenous peoples on matters of importance to them. This involves equitable sharing of resources and decision-making authority, including greater access to and ownership of land.

- To decentre non-Indigenous dominance of matters important to Indigenous people, by reducing the discriminatory assumptions, structures and processes that are the legacy of distorted relations.

In this centring/decentring work, there are immediate steps that can be taken by natural hazard agencies and research institutions. For example, appointing Indigenous people as staff, board members and establishing reference and advisory groups and creating enabling and accountability structures and processes, such as reporting and training (Weir, Neale \& Smith 2021). Institutional leadership is critical because these are systemic matters that involve inter-personal understandings and communication among staff (Ellemor 2011, p.6). Institutions are formed by people and misunderstandings are common between Indigenous and non-Indigenous people. There will be uncomfortable and enlightening encounters in shifting the status quo (Freeman et al. 2021). This is about beginning with who is at the table, who is supported to be there and what meanings and interpretations are heard and considered appropriate. From here, questions can then be discussed about what matters, what might be done about it and by whom.

For example, when recovery funds are being designed with farmers and businesses in mind, it is essential that Indigenous peoples' specific priorities are considered as well. These may be for the restoration of culturally important species and places as well as supporting early access to Country to gauge what has happened. The model for funding needs to be fit-for-purpose, co-designed with Indigenous people and funds prioritised 
" RESEARCH

for Indigenous organisations. This work involves considering Indigenous peoples' priorities, worldviews, organisational forms, skill sets, resources and legal responsibilities (Weir \& Duff 2017). The majority of existing models supporting Indigenous people on Country are designed for northern and central Australia and may not be fit-for-purpose in southern temperate Australia (Smith et al. 2021).

Research institutions and funding bodies must cease externalising Indigenous people from research (understood only as case studies) and acknowledge that Indigenous peoples have their own research expertise, organisations and priorities. This includes research processes and methods, design and governance and data sovereignty (AIATSIS 2020, Maiam nayri Wingara \& Australian Indigenous Governance Institute 2018, NMRHC 2018). Research institutions must support these while examining the structures and processes of their own disciplines, professional associations, institutions and curricula (Cavanagh \& Stanley 2021, Hemming et al. 2010, Weir et al. 2018).

To increase awareness, understanding and experience, important events such as NAIDOC, Mabo Day and Sorry Day provide context and vision as do texts by Indigenous authors and institutions such as AIATSIS (2018). There are also many resources online, including:

- Forums, organisations and peak bodies - traditional owner groups, land councils, corporate native title bodies, Elders councils; tv and radio broadcasting bodies; land and water representative organisations and networks; research bodies; and specific appointments such as the Aboriginal and Torres Strait Islander Social Justice Commissioner.

- Policies - Caring for Country ${ }^{2}$, Cultural Burning (Steffensen 2020) and land-based approaches to healing collective and individual trauma (Lowitja Institute 2020).

These suggestions and are not a result of comprehensive research but reflect particular expertise. Indeed, there is a need for comprehensive research about the Australian context (Thomassin et al. 2018). This paper cites the narrower matter of fire management and not the broad suite of natural hazards work that includes planning, preparation, response and recovery as well as resilience.

\section{Research, policy, practice and cultural change}

Public sector and research institutions are influential and closely related bodies. The content of university research and curricula largely determines the evidence available to it and the public sector, the qualifications of university and public sector staff and the kinds of researchers employed by government agencies (Weir et al. 2021b). Together with research-industry collaborations, the public sector and universities have built what is considered 'normal' in research, policy and practice. The absence of Indigenous people and their priorities in this area is indicative of the absence of Indigenous people as staff, especially in executive roles. This is a suggestion because there is no research evidence to draw on, nor are sufficient records kept (Neale et al. 2019).
The surge in interest in Indigenous peoples' fire management since 2020 is the most recent opportunity for natural hazard agencies and research institutions to undertake and demonstrate authentic change with Indigenous peoples. In this, Indigenous people risk their fire management practices being co-opted and appropriated without support for the governance, knowledge, Country and kin that give meaning to these practices. This is another experience of dispossession. While it is generally better to make mistakes than not try, Indigenous people have good reason not to trust governments and research institutions. There are extensive histories and geographies of erasure and Indigenous people will avoid non-Indigenous institutions because of experiences of racism and associated trauma (Doyle et al. 2018). As Neale and co-authors (2020) warn:

... government, and research institutions should not ask Indigenous people, who live with two centuries of colonisation and discrimination, "How can your knowledge improve our resilience?' Instead, they should ask 'How can we support Indigenous peoples and their engagements with natural hazard management as part of their and our resilience?'

Unfortunately, many findings from inquiries into the summer bushfires in 2019-20 are still qualified and constrained by assumptions that do not understand Country. Country is the domain of all living things, including all people (Graham 2007, Cavanagh \& Stanley 2021). Country is the agenda, not an agenda item. It is the paper that the list is written on, not an item on the list. Understanding Country requires non-Indigenous people to be part of an open dialogue; one that does not presume where that dialogue might go.

With Country as the frame for knowing and governing, it is clear why Indigenous leaders argue that the land must come first in hazard mitigation. The current arrangement places human lives first, then property and the environment last. When Indigenous people foreground the land, this is not to dismiss human lives and property, but to appreciate that taking care of lives and property requires first taking care of Country (Steffensen, in Weir 2020). This is not unrealistic or naïve work. It is of profound importance and it is already influencing the natural hazard sector. It is leading to natural hazard practices and research that are not just uniquely Australian, as they already are, but also embedded in respectful relations with Indigenous people and Country.

There are challenges both in play and ahead. For example, the 2020 Royal Commission into National Natural Disaster Arrangements ${ }^{3}$ was constrained by terms of reference focused solely on Indigenous fire practices (Binskin et al. 2020). It also recommended learning from Indigenous peoples' 'local knowledge', not understanding that Indigenous knowledge is not just local. These were opportunities lost. Nevertheless, the Royal Commission is a clear break from the absences that came before (Binskin et al. 2020). The concept paper for discussion published

2. See, for example, the Northern Land Council website for their Caring for Country policies.

3. Royal Commission into National Natural Disaster Arrangements, at: https://naturaldisaster.royalcommission.gov.au. 
by the Bushfire and Natural Hazards Cooperative Research Centre, Framing a Disaster Resilience Research Portfolio, did not mention Indigenous peoples in its research themes, however, in response to feedback from Indigenous scholars, it has contracted work to alter the focus (BNHCRC 2021). Scholars writing about cultural burning practices in southern temperate Australia are tracking the movement from deficit approaches to building relationships with Indigenous peoples. All this work shows that it is possible to reduce the ongoing effects of distorted relations with Indigenous peoples across research, policy and practice structures and processes.

\section{Conclusion}

There will be irresolvable tensions in the relationships between Indigenous and non-Indigenous co-located political-legal groups. This tension should not be avoided or ignored but grasped as central to the pursuit of just terms, including in the context of natural hazards. While it is not possible to make good for all that has happened, it is possible and desirable that non-Indigenous people and institutions acknowledge what has happened, take these matters seriously and demonstrate good faith by undertaking to work otherwise.

\section{References}

Ali T, Buergelt PT, Paton D, Smith JA, Maypilama EL, Yungirrna D, Dhamarrandji S \& Gundjarranbuy R 2021, Facilitating Sustainable Disaster Risk Reduction in Indigenous Communities: Reviving Indigenous Worldviews, Knowledge and Practices through TwoWay Partnering. International Journal of Environmental Research and Public Health, vol. 18, no. 3, p.855.

Altman J \& Markham F 2015, Burgeoning Indigenous land ownership: Diverse values and strategic potentialities, in Brennan, $S$ Davis, M Edgeworth, B \& L Terrill (Eds), Native Title from Mabo to Akiba: A Vehicle for Change and Empowerment?, The Federation Press, Sydney, Australia, pp.126-142.

Atkinson G \& Storey M 2016, The Aboriginal Heritage Act 2006 (Vic.): A glass half full..? In PF McGrath (Ed.), The Right to Protect Sites: Indigenous Heritage Management in the Era of Native Title, pp.111-136. AIATSIS Research Publications, Canberra.

Australian Institute of Aboriginal and Torres Strait Islander Studies (AIATSIS) 2020, AIATSIS Code of Ethics for Aboriginal and Torres Strait Islander Research, AIATSIS, Canberra.

Binskin M, Bennett A \& Macintosh A 2020, Royal Commission into National Natural Disaster Arrangements report. Commonwealth of Australia.

Cavanagh V 2021, Vanessa's Story in Weir JK, Freeman D and Williamson B (eds) Cultural Burning in Southern Australia, Report number: 687.2021, Bushfire and Natural Hazards CRC, Melbourne.

Cavanagh V \& Standley P 2020, Walking in the Landscapes of Our Ancestors - Indigenous Perspectives Critical in the Teaching of Geography. Interaction, vol. 48, no. 1, pp.14-16.

Commonwealth of Australian Governments (COAG) 2011, National Strategy for Disaster Resilience. Policy Document. Council of Australian Governments: Canberra.
Cole L, Dovers S, Eburn M \& Gough M 2017, Major post-event inquiries and reviews: Review of recommendations, Bushfire and Natural Hazards CRC, Melbourne.

Doyle J, Atkinson-Briggs S, Atkinson P, Firebrace B, Calleja J, Reilly R, Cargo M, Riley T, Crumpen T \& Rowley K 2016, A prospective evaluation of first people's health promotion program design in the Goulburn-Murray rivers region. BMC Health Services Research, vol. 16, no. 1, p.645.

Ellemor H 2005, Reconsidering emergency management and indigenous communities in Australia. Environmental Hazards, vol. 6, no.1, pp.1-7.

Freeman D, Williamson B and Weir JK 2021, Cultural Burning and Public Sector Practice in the Australian Capital Territory, Australian Geographer, vol. 52, no. 2, pp.111-129.

Bodkin-Andrews G \& Carlson B 2016, The legacy of racism and Indigenous Australian identity within education, Race Ethnicity and Education, vol. 19, no. 4, pp.784-807.

Graham M 2008, Some Thoughts on the Philosophical Underpinnings of Aboriginal Worldviews. Australian Humanities Review, vol. 45, pp.181-194.

Haynes K, Bird DE \& Carson DB 2014, Indigenous experiences and responses to Cyclone Tracy. In Palutikof JP, Boulter SL, Barnett J \& D Rissik (Eds) Applied studies in climate adaptation, Wiley, Chichester, pp.206-297.

Hemming S, Rigney D \& Berg S 2010, Researching on Ngarrindjeri Ruwe/Ruwar: Methodologies for positive transformation. Australian Aboriginal Studies, vol. 2, pp.92-106.

Krieg A 2009, The Experience of Collective Trauma in Australian Indigenous Communities. Australasian Psychiatry, vol. 17, pp.S28-S32.

Kwaymullina A 2016, Research, Ethics and Indigenous Peoples: An Australian Indigenous Perspective on Three Threshold Considerations for Respectful Engagement. AlterNative: An International Journal of Indigenous Peoples, vol. 12, no. 4, pp.437-49.

Laidlaw P, Spennemann DHR \& Allan C 2008, Protecting cultural assets from bushfires: A question of comprehensive planning. Disasters, vol. 32, no, 1, pp.66-81.

Lambert S \& Scott J 2019, International Disaster Risk Reduction Strategies and Indigenous Peoples. International Indigenous Policy Journal, vol. 10, no. 2, pp.1-21.

Latulippe N \& Klenk N 2020, Making room and moving over: knowledge co-production, Indigenous knowledge sovereignty and the politics of global environmental change decision-making. Current Opinion in Environmental Sustainability, vol. 42, pp.7-14.

Lay K 2020, After the flames - 'Community Reflections: Voices from the 2019-2020 bushfire season', Bushfire Recovery Victoria.

Maiam nayri Wingara \& Australian Indigenous Governance Institute 2018, Indigenous Data Sovereignty: Communique Indigenous Data Sovereignty Summit. 
McGregor D 2017, From 'Decolonized' To Reconciliation Research in Canada: Drawing from Indigenous Research Paradigms. ACME: An International Journal for Critical Geographies, vol. 17, no. 3, pp.810-831.

McLeod R 2003, Inquiry into the Operational Response to the January 2003 bushfires in the ACT. ACT Government, Canberra.

Moggridge B 2019, Indigenous Engagement Protocols for Threatened Species Researchers, Threatened Species Recovery Hub, National Environmental Science Program.

Neale T, Smith W \& Leavesley A 2019, Indigenous people in the natural hazards management sector: examining employment data. Australian Journal of Emergency Management, vol. 34, no. 3, pp.15-16.

Neale T, Weir JK \& Smith W 2020, Submission to the NSW Independent Bushfire Inquiry, 17 April 2020.

National Health Medical Research Council (NHMRC) 2018, Ethical Conduct in Research with Aboriginal and Torres Strait Islander Peoples and Communities: Guidelines for Researchers and Stakeholders.

Norman H 2018, Return of public lands to Aboriginal control/ ownership. In Aboriginal Affairs NSW (Ed.), Transforming the relationship between Aboriginal peoples and the NSW Government: Aboriginal Affairs NSW research agenda 2018-2023.

Owens D \& O'Kane M 2020, Final Report of the NSW Bushfire Inquiry. Department of Premier and Cabinet, NSW.

Pascoe B \& AIATSIS 2018, The Little Red Yellow Black Book: An Introduction to Indigenous Australia, Aboriginal Studies Press, Canberra.

Reo NJ, Whyte KP, McGregor D, Smith MA \& Jenkins JF 2017, Factors That Support Indigenous Involvement in Multi-actor Environmental Stewardship. AlterNative: An International Journal of Indigenous Peoples, vol. 13, no. 2, pp.58-68.

Sangha K, Edwards, \& Russell-Smith J 2019, Long-term solutions to improve emergency management services in remote communities in northern Australia. Australian Journal of Emergency Management, vol. 34, no. 2, pp.23-31.

Smith W, Neale T \& Weir JK 2021, Persuasion without policies: The work of reviving Indigenous peoples' fire management in southern Australia, Geoforum, vol. 120, pp.82-92.

State of Victoria 2020, Victorian Government Aboriginal Affairs Report, Victoria.

Steffensen V 2020, Fire country: How Indigenous fire management could help save Australia. Hardie Grant Books, Melbourne.

Strelein L, Dodson M \& Weir JK 2001, Understanding nondiscrimination: native title law and policy in a human rights context. Balayi: Culture, Law and Colonialism, vol. 3, pp.113-48.

Strelein L, Hassing C, Smyth L \& Barcham C 2019, AIATSIS Submission - Inquiry into the Opportunities and Challenges of Engagement with Traditional Owners in Economic Development of Northern Australia. AIATSIS, Canberra.
Sullivan C 2020, 'Who holds the key?: negotiating gatekeepers, community politics, and the 'right' to research in Indigenous spaces, Geographical Research, vol. 58, no. 4, pp.344-354.

Teague B, McLeod R \& Pascoe S 2010, The 2009 Victorian Bushfires Royal Commission. Parliament of Victoria.

The Lowitja Institute 2020, We nurture our culture for our future, and our culture nurtures us, Report, The Close the Gap Campaign Steering Committee for Indigenous Health Equality.

Thomassin A, Neale T \& Weir JK 2018, The Natural Hazard Sector's Engagement with Indigenous Peoples: A Critical Review of CANZUS Countries: Critical Review of CANZUS Countries. Geographical Research, vol. 57, no. 2, pp.164-77.

Veland S, Howitt R \& Dominey-Howes D 2011, Invisible institutions in emergencies: evacuating the remote Indigenous community of Warruwi, Northern Territory Australia, from Cyclone Monica. Environmental Hazards, vol. 9, no. 2, pp.197-214

Weir JK 2020, Bushfire lessons from culture burns, Australian Journal of Emergency Management, vol. 35, no. 3, pp.11-12.

Weir JK, Neale T \& Smith W 2021, Hazards, Culture and Indigenous Communities: Final Report. Bushfire and Natural Hazards Cooperative Research Centre, Melbourne.

Weir JK, Neale T \& Clarke EA 2021b, The recalibration of our relationships with science (and nature) by natural hazard risk mitigation practitioners. Environment and Planning E: Nature and Space.

Weir JK, Sutton S \& Catt G 2020, 'Indigenous peoples' fire management and the theory/practice of disaster justice', in A Lukasiewicz and C Baldwin (eds), Natural Hazards and Disaster Justice: Challenges for Australia and its Neighbours, Palgrave Macmillan: Chicago, pp.299-317.

Weir JK \& Duff N 2017, Who is Looking after Country? Interpreting and Attributing Land Management Responsibilities on Native Title Lands. Australian Journal of Public Administration, vol. 6, no. 4, pp.426-442.

Williamson B, Markham F \& Weir JK 2020, Aboriginal peoples and the response to the 2019-2020 bushfires, Working Paper No. 134/2020, Centre for Aboriginal Economic Policy Research, Australian National University, Canberra.

\section{About the authors}

Bhiamie Williamson is a Euahlayi man, a member of the Australian Capital Territory Bushfire Council and an independent expert on the NSW Forest Monitoring and Improvement Program Steering Committee.

Dr Jessica Weir is a non-Indigenous academic who has worked with Indigenous people on land and water research issues for over 20 years. She is a Senior Research Fellow at the Institute for Culture and Society, Western Sydney University. 